\title{
Is There a Need for Healing in the Classroom? Exploring Trauma-Informed Education for Aboriginal Mature Students
}

\author{
Elaine Mordoch and Rainey Gaywish \\ Aboriginal Focus Programs, University of Manitoba
}

\begin{abstract}
In this paper, we describe a perplexing pattern of behaviours in mature Aboriginal students in university studies who appear capable of being successful to complete course work, but fail due to incompletion of academic work. Despite numerous strategies to provide students with opportunities for success, these students' behaviours remain perplexing. Considering the prevalence of trauma (accident, violence, suicide) in the Aboriginal population and the intergenerational trauma of the residential school experience, we examine trauma-informed care principles and their adaption to educational systems as a potential strategy to mitigate this problem. A conceptual framework based on an Indigenous knowledge perspective of Four Lodges guides the discussion of this issue.
\end{abstract}

Keywords: mature students, Aboriginal students, intergenerational trauma, residential school, care 


\title{
Is There a Need for Healing in the Classroom? Exploring Trauma-Informed Education for Aboriginal Mature Students
}

\begin{abstract}
Rhonda is a 45-year-old woman from a remote Northern reserve. At her request, Rhonda's First Nation has supported her to enroll in a continuing education program that was directly related to her role in her community. Rhonda travels to the city to attend 7 days of classes for one of her courses. She does not let the instructor know until she arrives at the classroom that she has not completed the pre-class assignment; she does not provide an explanation. During the week, Rhonda is actively engaged in the classroom learning, and completes most of the coursework due each day. At the end of the 7 days, she goes home with two assignments, one, an academic paper on a series of readings, is due in 2 weeks. Two months later, after several extensions, Rhonda admits she has not started her paper. As a result, despite her hard work in the classroom, Rhonda is not successful in completing the course.
\end{abstract}

In this paper, we initiate a discussion of whether the historical trauma experienced by Aboriginal people could be an underlying source of the behavioural pattern described above. Rhonda is a fictitious student; this description was constructed as a case example typifying an observed pattern that is negatively impacting the success of students in one particular program, a 2-year diploma offered as an off-campus program for students who live and work in Aboriginal community settings. The issue could be stated basically as student failure to submit required post-course writing assignments. It is important to note that students' failure to submit academic papers is not an issue that is unique in programs for Aboriginal people or cohort programs, but simply could be more evident where it occurs in cohort groups of students studying outside of the typical full-time student on-campus experience. However, we are beginning an exploration of whether the effects of historical trauma experienced by Aboriginal people can help to explain the observed behaviour in Aboriginal students, with the intention of developing interventions that are more effective. We present this exploration from the perspectives of both administrator and teacher, with experience spanning 20 years in administration and 10 years in teaching Aboriginal-specific university programs.

\section{The Four Lodges}

An Indigenous Knowledge (IK) approach is being used to frame the discussion, derived in part from Anishinabe teachings and perspectives shared in The Mishomis Book: The Voice of the Ojibway (Benton Banai, 1979), the Four Directions Teaching (2006), as well as from our knowledge and experiences. The framework consists of four interconnected perspectives or lodges situated in turn in the East, South, West, and North. It is not a rigid model, but provides a way to organize an approach to the issue being discussed. Starting in the East, we engage in the Talking Lodge, where we discuss our common concerns and identify the issue (Medicine of the East direction-Tobacco: What do we seek to be answered?). We, then, move to the South, to the Planning Lodge, and discuss how to proceed. In this lodge, we seek to determine what resources (knowledge and support) we have available to apply to finding a resolution. We identify what resources are needed and from where (Medicine of the South direction-Cedar: What nurturing is needed?). Then, we move to the West, the Teaching Lodge, where we seek out the knowledge and support we identified, in the case of this project, our own experience as educators, along 
with existing research (Medicine of the West direction-Sage: How do we attain clarity of mind and heart? What wisdom do we have, what can we draw on from those who went before us?) We move to the final and fourth direction, the North, to the Healing Lodge. There, in the north direction, we consider the knowledge we have gathered in relation to the issue in order to arrive at an understanding of how to resolve the identified concerns (Medicine of the North directionSweetgrass: How do we bring about balance, positive energy?).

In this holistic approach, we complete the cycle of movement through the Four Lodges, with the understanding that if the knowledge gained through the experience generates new questions or issues to be explored, the process through the cycle can then begin anew. The second time through the cycle the process might be accomplished with a greater level of ease, awareness, and strengthened capacity to focus on questions or issues that surface.

\section{The Talking Lodge: What Do We Seek to be Answered? Medicine-Tobacco}

Starting in the East, we engage in the Talking Lodge, where our common concerns are discussed and the issue identified. The medicine of the East direction is Tobacco: What do we seek to be answered?

We began to notice a pattern emerging in the program (offered for over 10 years) where some students, whose classroom participation and coursework clearly demonstrated the ability to learn the course content, were failing because they did not submit the final course tasks or papers. Over time, a range of student support interventions were developed and used in the program, including offering encouragement, individual and group tutorial support, extensions, and counselling services. Great attention was given to the design of appropriate assignments with sensitivity to cultural relevance and the course delivery method. These strategies have been valuable in supporting student success in the program, but they have not had the desired impact on the issue being discussed in this paper. In addition to missed deadlines for submitting final course tasks or assignments, procrastination and a lack of communication with instructors or program staff regarding the issue are consistent themes.

Program evaluations and statistics show that the program design does result in success for the majority of students. Yet, a number of seemingly capable students do not complete the course work and, consequently, lose the credit for the course. In attempting to understand the reasons behind this phenomenon, certain questions arise. Do the students who fail to complete their assignments undervalue the learning associated with particular courses, and are, thus, not motivated to complete? Are they lacking fundamental skills? Are they unable to prioritize or are they overwhelmed? Discussions and attempted interventions with the students in this program do not indicate an undervaluing of the learning or the credential being sought, or any less desire to be successful in the program than that of students who are completing their course assignments. The lack of success to mitigate this issue, despite multiple administrative and educational interventions, indicates that there are other factors impacting students that we have yet to identify and address.

The recently established Truth and Reconciliation Commission on Residential Schools is having a direct impact on discussions about the role that residential schooling continues to have in the education of Aboriginal people at all levels. A growing understanding of residential 
school trauma and its legacy led us to begin to discuss whether the long-term effects of trauma might be the underlying cause of the behaviours we were witnessing in the course completion, and if so, to explore what that meant for potential interventions. Recent literature indicates that the historic experiences of colonization and trauma experienced by Aboriginal people in Canada is a source of intergenerational post-traumatic stress and significant levels of post-traumatic stress disorders (PTSD) in the Aboriginal population (Bombay, Matheson, \& Anisman, 2009).

Fiske (2009) notes that the childhood sexual abuse experiences of residential schools has often been viewed as a private place of abuse and has only recently shifted to a public space acknowledging political oppression wherein personal trauma experiences are now a collective trauma. As noted by Fiske (2009), the location of the problems of everyday life, fraught with dysfunction and personalized suffering within the context of collective trauma experiences, reconfigures marginalized histories as honourable collective history. Many Aboriginal people are now coming to embrace this reconceptualization of collective trauma. The process of doing so may entail struggle much like populations identified in Friere's (2011) classical work. In working towards liberation from oppression, education may highlight the experience of oppression but may not provide the tools to truly engage oppressed societies to begin to collectively react (Friere, 2011).

This discussion raises further questions: Does recent research on Residential School trauma explain the described pattern of student behaviours? If residual, intergenerational Residential School trauma is the issue, what types of intervention can ameliorate its impact on student success? Are the ideas of Friere's educational principles part of the discussion? Are students disillusioned or overwhelmed by their collective place in Canadian society? Is education assisting them to move forward from a position of raised consciousness?

\section{The Planning Lodge: What Nurturing (Knowledge and Support) is Needed? Medicine- Cedar}

We move to the South, to the Planning Lodge, and discuss how to proceed. In this Lodge, we seek to determine what resources (knowledge and support) we have available to apply to finding a resolution. We identify what resources are needed and from where. The medicine of the South direction is Cedar: What nurturing is needed?

We realized that we did not have enough information about trauma, or about the impact of Residential Schools on current generations of Aboriginal people, or how intergenerational trauma might be impacting on the students who were expressing the behaviours of concern. An initial search revealed three areas of research on trauma that could be helpful in furthering this discussion: trauma definitions, post-traumatic stress disorder (PTSD), and complex posttraumatic stress syndrome.

Trauma is defined as,

Experiences or events that by definition are out of the ordinary in terms of their overwhelming nature. They are not merely stressful,[sic] they are shocking, terrifying 
and devastating to the victim, resulting in profoundly upsetting feelings of terror, shame, helplessness and powerlessness. (Courtois, 1999, p. 33)

Discussions of trauma have historically been veiled in controversy. Herman's (1997) classic work called Trauma and Recovery: The Aftermath of Violence from Domestic Abuse to Political Terror, describes a history that has at times forced discussion underground and denied the existence of trauma and its effects on the lives of traumatized people. Increased visibility of trauma and its long-term effects are associated with the women's liberation movement. Stories of childhood sexual abuse, physical violence, and domestic violence have emerged from the lived experience of women and children (Herman, 1997). Currently, there is growing recognition of the impact of traumatic childhood experiences on male children and a need to develop awareness and services for this population (Romano \& De Luca, 2006).

The diagnosis of post-traumatic stress disorder (PTSD) arises from personal exposure to an overwhelming traumatic event such as childhood sexual abuse, natural disaster, motor vehicle accident. PTSD may also be triggered by the witnessing of such events or hearing about a family member's traumatic experiences. The diagnostic criteria for PTSD consists of three core clusters of symptoms: avoidance of trauma related stimuli, re-experiencing of dreams, flashbacks, intrusive memories, and heightened arousal to environmental stimuli exhibited by decreased sleep, hyper-vigilance, exaggerated startle response, and poor concentration. These symptoms cause significant distress and impairment to the person's life ( American Psychiatric Association, 2000). Post-traumatic stress disorder (PTSD) was initially the diagnosis attributed to a myriad of symptoms related to the traumatic experience. Symptoms include hyperarousal, intrusion of thoughts, and avoidance and numbing defences. Women who have experienced childhood sexual trauma have increased incidents of PTSD and an increased likelihood of accident or injury. Comorbid disorders of anxiety, depression, and substance abuse are also correlated with a history of childhood sexual abuse (Nehls \& Sallmann 2005). Mulvihill (2005) conducted a multidisciplinary review on the health impact of childhood trauma and concluded that evidence suggests there are significant adverse effects on social, physical, cognitive, and emotional development. In addition, childhood abuse has a strong correlation with health care utilization and adult health problems (Chartier, Walker, \& Naimark, 2007).

Complex post-traumatic syndrome, also known as disorders of extreme stress not otherwise specified (DESNOS), are human responses to ongoing traumatic experiences. Complex trauma takes into account prolonged, severe and massive trauma and may more aptly fit the situations of some Aboriginal peoples, particularly residential school survivors (Sochting, Corrado, Cohen, Ley, \& Brasfield, 2007). A growing body of research on the impact of residential schools, and a developing language to describe the historical or intergenerational impact of residential school trauma, may fit as DESNOS, but this research is still very much in the form of theoretical discussion (Bombay et al., 2009 p. 24). However, the literature points to historical trauma and ongoing trauma from chaotic childhood experiences of neglect, sexual and physical abuse, domestic violence, and loss of culture, language, and land as contributing to a prolonged traumatization of Aboriginal people. Behaviours related to (EDONOS) include sense of hopelessness, withdrawal, paralysis of initiative, problems with affect regulation, and a sense of stigma, shame, guilt, and self blame (Herman, 1997), behaviours also identified by the legacy of residential school (Braesfield, 2001). The long-term effects of the residential school 
experience and the abuse within that system have resulted in disrupted community and family relationships and self-destructive behavior (Sochting et al., 2007).

Rates of exposure to trauma are elevated for Aboriginal people with a prevalence of $67 \%$ of males and $70 \%$ of females. The rate for females is significantly higher than the general population reflecting increased levels of increased sexual and physical violence (Manson, Beals, Klien, \& Corey, 2005). Further, two thirds of Aboriginal people reported experiencing a traumatic event with car accidents, suicide, and death most frequently described (Kirkmayer, Tait, \& Simpson, 2009). These statistics indicate that a considerable number of mature students can potentially be experiencing complex post-traumatic syndrome that results in behaviours that interfere with achieving their academic goals. Recent heightened sensitivity to cultural experiences has further suggested syndromes such as "totally discouraged syndrome" characterized by suicidal behaviours, alcoholism, neglect of family, and lack of social responsibility. In addition, residential school syndrome has been recognized as similar to PTSD but differing due to the cultural impact. This syndrome presents itself in diverse ways through social and psychological issues (Braesfield, 2001). Students working in the front lines may encounter their own personal issues, past and present, and vicariously experience the traumas of people whom they are trying to help, thus compounding the traumas that front line workers face.

\section{The Teaching Lodge: How Do We Come to Know; How Do We Attain Clarity of Mind and Heart? The Medicine - Sage}

We then move to the West, the Teaching Lodge, where we seek out the knowledge and support that we identified, in the case of this project, through our own experiences as educators and administrator along with existing research. The Medicine of the West direction is Sage: How do we attain clarity of mind and heart? What wisdom do we have, what can we draw on from those who went before us?

While education and therapy are viewed as distinct entities, education needs to respond to the potential of effects of trauma, both historical and ongoing, within classroom settings. In light of the statistical evidence and accounts of lived experience of Aboriginal mature students, it is reasonable to conclude that a percentage of Aboriginal students will be experiencing the effects of both historical trauma and ongoing traumatic events. Research on literacy classes supports a strong link between trauma and student profiles. Women from abusive backgrounds may view education as a way to control and improve their lives and look to the classroom as a safe place. However, education policies determining literacy education limit recognition of the reality of violence in students' lives and ways to understand how this violence may affect students' abilities to learn (Horsman, 2004). Women students living with violence, past and present, may experience fear, related to childhood experiences that have humiliated them, when in the student role. Societal put downs related to race and oppression within the dominant society may contribute to anger and frustration that is exhibited in the classroom (Horsman, 2004).

Students who are living with trauma may use a considerable amount of energy to conceal their situations and have less energy to engage in the classroom, needing all of their energy to get through the day (Collins Sitler, 2008). Students may have problems with trust, often in an "all or nothing” type attitude where they will trust inappropriately or react with hostility (Horsman, 
2004). Trauma, as stated by Herman (1997), robs people of control, connection, and meaningconcepts that help to motivate people to set and attain goals. Students may be sensitive to feelings of incompetence and devalue themselves and their efforts. We suggest that intergenerational and present potential for trauma and its effects on learning behaviours be considered in education efforts. Smye, Browne, Varcoe, and Joweski (2011) note that the historical and structural inequities that influence the health of Aboriginal people have contributed to a greater risk for trauma, violence and substance abuse within Aboriginal people. The historical oppression of Aboriginal peoples, inclusive of the residential schools and their legacy of intergenerational trauma, compounded by common ongoing trauma experiences, either personally or vicariously through front line work within Aboriginal communities, requires serious consideration in the presentation of student behaviours and within education efforts.

Student profiles. Our experience indicates that mature Aboriginal students frequently identify trauma issues, including intergenerational trauma related to residential school experiences in themselves and/or family of origin; recovery from addiction; and childhood histories of sexually, physical, emotional abuse, and neglect. Students often bear witness to ongoing trauma issues in the communities within which they work and are, therefore, exposed to vicarious retraumatization. Students' revelations of such sensitive issues generally occur in sharing circles that are used to build cultural congruence within the course delivery or in selfawareness exercises used in the development of counselling skills. Students who are healing from their own trauma issues are often simultaneously working with people who are currently experiencing trauma issues, and may also be living in communities facing ongoing trauma and grief issues. The role of a helper in the community is demanding and in order to provide help to others, the helper must be well and able to practice self-care. Students who are learning to become health care paraprofessionals and who also may be on their own personal journeys may experience behavioural problems related to their life circumstances and past trauma histories. Within the larger societal context, Aboriginal communities may be in the process of "recuperation" wherein they are "taking back" their identities and losses due to colonization (Silver, 2004). This process is multi-layered and complex and it may be difficult to negotiate; a consensus among Aboriginal communities on what this process may entail has not been reached. While the process of recuperation is ultimately potentially healing, it is not without political challenges that contribute to students' accumulative stresses and should be considered within the educational setting ( Silver, 2004).

\section{The Healing Lodge: How Do We Bring About Positive Energy? Medicine-Sweetgrass}

We move to the final and fourth direction, the North, to the Healing Lodge. There, in the north direction, we consider the knowledge we have gathered in relation to the issue in order to arrive at an understanding of how to resolve the identified concerns. The medicine of the North direction is Sweetgrass: How do we bring about balance, positive energy?

Trauma-informed care and trauma-informed education. Currently, there is a movement in health care to organize trauma-informed care. This movement operates under the assumption that most people who are seeking services have experienced trauma. Traumainformed health care professionals consider how trauma can affect individuals seeking services and organize their services to recognize trauma and to avoid retraumatization of the person 
(Elliot, Bjelajac, Fallot, Markoff, \& Glover Reed 2005). The main principles of care are: recognition of the impact of violence and how coping is affected; recovery from trauma is possible; use of an empowerment model, relationships are key and should be developed in a context of hope; need for respect, acceptance and safety; adaptations not pathology are highlighted, and survivors of trauma are involved in designing and evaluating services (Elliot, Bjelajac, Fallot, Markoff, \& Glover Reed, 2005). Specifically, trauma-informed educators, borrowing from the principles of trauma-informed care, would recognize the vulnerabilities of trauma survivors, work towards avoiding retraumatization within the delivery of education, and promote healing and well-being based on evidence derived policy and interventions (Harris \& Fallot, 2001).

\section{Conclusion}

Educators in all areas are challenged by interaction with students who have experienced trauma and violence in their lives. Considering the suggested prevalence and impact of trauma on Aboriginal people (Kirmayer et al., 2003) and that a number of mature Aboriginal students are affected by ongoing and historical trauma, we propose that principles of trauma-informed care be used in education. Aboriginal students may also experience racism in their daily lives and a sense of being shamed, excluded, and silenced-experiences that affect classroom behaviours and may present as barriers to learning (Horsman, 2004). We suggest that the principles of trauma-informed care may be transferable to the educational setting and will be useful to assist students who are potentially affected by complex traumas within their lives and their communities. Collins Sitler (2008) calls for teaching with awareness, which entails acknowledgement of the possibility of trauma in students' lives and recognition of the classroom behaviours that may indicate a history of trauma or current trauma in students' lives. Herman's (1997) classic work, which today remains informative on trauma experiences, indicates that trauma experiences fracture connections, dilute meaning, and result in a sense of loss of control. By understanding trauma and its potential effects on students, educators will be better able to assist these students to engage in their learning and to thereby, attain success.

A philosophy of universal precautions in using the principles of trauma-informed care in education may be helpful to alleviate the problems of seemingly capable students not completing their work and resulting in their failure. Universal precautions is a term introduced to health care delivery at the height of the HIV/AIDS epidemic which decreed that all patients coming into the health care system could be potential carriers of HIV/AIDS and that health care providers take precautions by gloving with all patients versus waiting for confirmed diagnosis. Universal precautions within the health care setting served two purposes: to protect the health care worker and to prevent the inadvertent spread of disease. Universal precautions applied to complex trauma within educational settings have the potential to raise awareness of complex trauma symptoms and its effect on behaviours that can be perplexing in the classroom.

In addition, trauma-informed educators may assist the current generation of mature Aboriginal students to overcome their circumstances and maximize their potential. Because students in our program often maintain multiple roles as front line workers, family members, and students, it is crucial to consider strategies and policies that will assist students to succeed, to honour their lived experiences, and to maintain their role as helpers. We propose that trauma- 
informed care in education may be part of the solution to assist students who cannot complete their work or communicate with the instructor within a reasonable time. Educators familiar with trauma-informed education may identify strategies that can increase capacity and maximize potential within the population of mature Aboriginal students and other mature students who may experience perplexing problems. The effects of trauma are not contained within the health care system, but can transfer to all areas of life inclusive of education. Similar to gloving for universal precautions against blood borne infections, universal trauma-informed principles, when applied to education, have the potential to enable educators to: foster an environment where all students are respected, informed, connected, and hopeful in regards to trauma experiences; identify the relationship between trauma and symptoms associated with having experienced trauma; and emphasize the need to integrate and develop trauma-informed educational policies to assist students and faculties (Harris \& Fallot, 2001).

We propose that research be conducted, firstly, to assess students' perceptions of their trauma experiences and its effects on their academic performance; and that trauma-informed, education principles be developed and researched for their efficacy in addressing behavioral difficulties within the educational process. We further propose that, in attending to this discussion on the potential impact of trauma on the learning experiences of oppressed people, reconsideration of Friere's work and current adaptions of that work be reviewed against this backdrop of historical trauma experiences and their long term effects. To effect social change, Settee (2011) states that, education and the acknowledgement of trauma due to the effects of colonialism-including historical trauma-are important. It is equally important to discern the hope and strength that is present in many communities and in our students. As such, it is significant to try and develop new understandings of student behaviours and ways to more effectively intervene. Educational interventions must be sensitive to trauma experiences and empower the current generation of mature students. Education is not neutral but has a potential for empowering action (Friere, 2011). In the situation that we describe, we suggest that traumainformed education has the capacity to enhance student's abilities to both complete their studies and to fulfill their concurrent roles as front line community workers. Thus, the benefits of doing so will potentially affect both the educational and service-delivery arenas. 


\section{References}

American Psychiatric Association (2000). Diagnostic and statistical manual of mental disorder (4th ed., text revision). Washingon, D.C.

Benton Banai, E. (1979). The Mishomis book: The voice of the Ojibway. Hayward, Wisconsin: Indian Country Communications Inc.

Bombay, A., Matheson, K., \& Anisman, H. (2009). Intergenerational Trauma: Convergence of multiple processes among First Nations peoples in Canada. Journal of Aboriginal Health, 5(3). National Aboriginal Health Organization (NAHO), Ottawa, ON. Accessed from: http://www.naho.ca/journal/2009/11/03/intergenerational-trauma-convergen...

Braesfield, C. R. (2001). Residential school syndrome. BC Medical Journal, 43(2), 78-81.

Chartier, M. J., Walker, J. R., \& Naimark. B. (2007). Childhood abuse, adult health, and health care utilization: Results from a representative community sample. American Journal of Epidemiology, 165 (9), 1033-1038.

Collins Sitler, H. C. (2008). Teaching with awareness: The hidden effects of trauma on learning. The Clearing House, 82(3), 119-123.

Courtois, C. (1999). Recollections of sexual abuse. Treatment, principles and guidelines. New York: W. Norton \& Company.

Elliot, D. E., Bjelajac, P., Fallot, R. D., Markoff, L. S., \& Glover Reed, B. (2005). Traumainformed or trauma-denied: Principles and implementation of trauma-informed services for women. Journal of Community Psychology, 33(4), 461-477.

Fiske, J. (2009). Placing violence against first nations children: the use of space and place to construct the (in)credible violated subject. In L. J. Kirkmayer \& G. Guthrie Valaskakis(Eds.), Healing traditions: The mental health of Aboriginal people in Canada (pp. 140-59). Vancouver: UBC Press.

Friere, P. ( 2011). Pedagogy of the oppressed (30th anniversary edition). New York: Continuum.

Harris, M., \& Fallot, R. D. (2001). Using trauma theory to design service systems. San Francisco: Jossey-Bass.

Herman, J. (1997). Trauma and recovery: The aftermath of violence from domestic abuse to political terror. New York: Basic Books.

Horseman, J. (2004). “But is it education?” The challenge of creating effective learning for survivors of trauma. Women's Studies Quarterly 1 \& 2,130-146. 
Kirmayer, L., Simpson, C., \& Cargo, M. (2003). Healing traditions: Culture, community and mental health promotion with Canadian Aboriginal peoples. Australasian Psychiatry, 11 (Supplement s1).

Kirkmayer, L. J., Tait, C. L., \& Simpson,C. (2009). The mental health of indigenous people. In L. J. Kirkmayer \& G. Guthrie Valaskakis (Eds.), Healing traditions: The mental health of Aboriginal people in Canada (pp. 3-35 ). Vancouver: UBC Press.

Manson, S. M., Beals, J., Klein, S. A., \& Croy, C. D. (2005). Social epidemiology of trauma among two American Indian reservations. American Journal of Public Health, 95 (5) 851859.

Mulvihill, D. (2005). The health impact of childhood trauma: an interdisciplinary review, 19972003. Issues in Comprehensive Pediatric Nursing, 28(2), 115-136.

National Indigenous Literacy Foundation. (2006). Four directions teaching. Retrieved from http://www.fourdirectionsteachings.com

Nehls, N., \& Sallmann, J. (2005). Women living with a history of physical and/or sexual abuse, substance use and mental health problems. Qualitative Health Research, 15(3), 365-381.

Romano, E., \& De Luca, R.V. (2006). Evaluation of a treatment program for sexually abused adult males. Journal of Family Violence, 21(1), 75-88.

Settee, P. (2011). The strength of women, Ahkameyimowak. Regina, SK: Couteau Books.

Silver, J. (2004). Community development in Winnipeg's inner city. Canadian Dimensions, 36(6) 36-38.

Smye, V., Browne, A., Varcoe, C., \& Josewski, V. (2011). Methadone maintenance treatment and the root causes of health and social inequities: An intersectional lens in the Canadian context. Harm Reduction Journal, 1477-1489.

Sochting, I., Corrado, R., Cohen, I., Ley, R., \& Brasfield, C. (2007). Traumatic pasts in Canadian Aboriginal people: Further support for a complex trauma conceptualization? BCMJ 49(6), 320-326. 